\title{
Long-Term Impact of New Calcium-Silicate-Based Sealer on Mineral Contents and Crystallinity of Radicular Dentin: An Ex Vivo Study
}

\author{
Sawsan T. Abu Zeid $\mathbb{D}^{1,2}$ Ragab E. Saif, ${ }^{1,2}$ Loai Alsofi, ${ }^{1}$ and Ruaa A. Alamoudi ${ }^{1}$ \\ ${ }^{1}$ Department of Endodontic, Faculty of Dentistry, King Abdulaziz University, Jeddah, Saudi Arabia \\ ${ }^{2}$ Endodontic Department, Faculty of Dentistry, Cairo University, Cairo, Egypt \\ Correspondence should be addressed to Sawsan T. Abu Zeid; sawsanabuzeid55@hotmail.com
}

Received 30 March 2020; Revised 9 July 2020; Accepted 29 July 2020; Published 13 August 2020

Academic Editor: Pedro D. Vaz

Copyright (c) 2020 Sawsan T. Abu Zeid et al. This is an open access article distributed under the Creative Commons Attribution License, which permits unrestricted use, distribution, and reproduction in any medium, provided the original work is properly cited.

\begin{abstract}
Introduction. This study aimed to evaluate the long-term impact of new calcium silicate-based sealer (HiFlow Bioceramic) compared to calcium hydroxide-based sealer (Sealapex) on mineral constituents and crystallinity of radicular dentin. Methods. Roots of multirooted maxillary molars were denuded their dentin from all covered cementum then longitudinally split. The dentin segments were divided into three groups covered with either HiFlow root canal sealer or Sealapex root canal sealer or kept untreated (control group). After complete setting of sealers, the radicular dentin of each group was stored in phosphate buffer solution or deionized water for 60 days and then examined with Fourier Infrared Spectroscopy, scanning electron microscope/energy dispersed X-ray and X-ray diffraction (XRD). Results. When the dentin was stored in phosphate buffer solution, compared with untreated dentin, Fourier transform infrared spectra showed insignificant increase in the amide I and phosphate, significant increase in carbonate area, and carbonate/phosphate ratio, while there was insignificant change in phosphate/amide I ratio of HiFlow-treated dentin, whereas Sealapex induced significant decrease in amide I area, phosphate area, and phosphate/amide ratio. Both sealers induced significant increase in crystallinity index and significant decrease in crystallinity percent. Energy dispersed X-ray showed decrease in calcium content by both sealers. The phosphate content was increased by HiFlow and decreased by Sealapex. Conclusions. The mineral composition and crystallinity of dentin were insignificantly changed by the long-term HiFlow treatment, whereas, markedly changes by Sealapex.
\end{abstract}

\section{Introduction}

Dentin is a mineralized tissue that forms the main bulk of tooth structure. It is composed of $60 \%$ inorganic minerals including apatite crystals, $30 \%$ organic collagenous/noncollagenous matrix protein, and $10 \%$ water. The crystallinity and mineral constituents of dentin have an impact on its integrity. Any changes in structural integrity following endodontic treatment may compromise the mechanical properties of the tooth and may lead to tooth weakening with increase the susceptibility of fracture $[1,2]$.

Root canal filling materials may also predispose to reduce the biomechanics of endodontically treated teeth $[3,4]$. Root canal sealer is essential to achieve fluid-tight seal, seal-off the root canal system, and fill the irregularities within the core filling material and between the material and dentin walls $[5,6]$.

Calcium hydroxide-based sealer was firstly introduced in 1940 [7]. It promotes alkaline $\mathrm{pH}$ with excellent antibacterial effect and allows suitable environment for periapical tissue healing. Bioceramic based root canal sealer is a new technology that was introduced in endodontic to enhance the bioactivity and improve the sealing ability of root filling materials [8]. Bioceramic HiFlow sealer is recently designed to meet the property of warm vertical technique. Its manufacture claimed that it sustains high heat resistance up to $220^{\circ} \mathrm{C}$ and exhibits high flow within dentinal tubules. Like 
other bioceramic sealers, it is composed of calcium silicate (di- and tri-calcium silicate) and calcium hydroxide.

Several studies advocated that high alkaline dental material includes calcium hydroxide that may adversely affect the physical properties of radicular dentin $[9,10]$ by decreasing mineral/amide I ratio [11]. Rosenberg et al. claimed that the dentin became weak by $23-43.9 \%$ following the application of calcium hydroxide filling [12]. Sawyer et al. 2012 concluded that both Biodentin and MTA plus significantly decreased the flexural strength of dentin within 2-3 months [13]. Another study reported that the dentin strength was decreased by 32-33 after calcium hydroxide and mineral trioxide aggregated treatment within 5 weeks [14].

Aim of the study is to evaluate the long-term impact of new calcium silicate-based sealer (HiFlow Bioceramic, Brasseler, Savannah, USA) compared to calcium hydroxidebased sealer (Sealapex, Kerr, SybronEndo, New York, USA) on mineral constituents and crystallinity of root dentin. The null hypothesis is that the root canal sealers induced calcium hydroxide by-product has no significant difference on the mineral constituents and crystallinity of radicular dentin compared with control untreated dentin.

\section{Materials and Methods}

2.1. Specimens Preparation. The procedure was approved from KAU Institute Ethical Committee (\# 01-2-20). Twenty caries free, triple rooted maxillary molars, from patients aged 30-50 years old, were collected for this study, from outpatients of oral surgery department clinic, at Faculty of Dentistry, King Abdulaziz University. All soft tissues on the root surfaces were manually removed using hand curette then ultrasonic cleaner (BioSonic UC125, Coltene, Switzerland). The teeth were autoclaved and stored in saline until used. The teeth were decoronated and the cementum layer was removed using diamond disc under copious water coolant [2]. The denuded roots were longitudinally split giving a total of 120 segments. For standardization, the root segments of each tooth were divided into three groups: group 1 was treated with premixed injectable Bioceramic HiFlow Sealer; group 2 was treated with Sealapex sealer, according to manufacture instructions and equal amount of base and catalyst paste of sealer was mixed. The sealers were applied on all dentin surfaces (around $10 \mathrm{mg}$ weight). Group 3 was left untreated to serve as control. All specimens were stored in an incubator for 48 hours, at $37^{\circ} \mathrm{C}$ and $100 \%$ humidity for complete setting of the root canal sealers.

After incubation period, the root segments of each group were subdivided into two subgroups ( $N=20$ /group); subgroup (A) was stored in vials containing phosphate buffer solution (PBS), while subgroup (B) was stored in deionized water. The solutions were refreshed every 3 days. After 60 days, all specimens were cleaned by automated brush (Prophy brush, Young Dental, Gujarat, India) and ultrasonic cleaner to remove sealers, rinsed with deionized water, dried in an incubator for 24 hours, and subjected to different analysis.
2.2. Fourier Transform Infrared (FTIR) Spectroscopy Analysis. The root canal surface of each sample was investigated using FTIR spectroscopy (Vertex 70, Bruker, Germany) in the spectra range $4000-400 \mathrm{~cm}^{-1}$ at $4 \mathrm{~nm}$ resolution. Three spectra were obtained from different area of each sample with repeated scan to verify the result. The mineral contents and collagen (amide I) of dentin structure were analyzed. After baseline was obtained, deconvolution of the spectra at $1800-800 \mathrm{~cm}^{-1}$ was performed. The integrated area under amide I, $v_{1} v_{3}$ phosphate, and $v_{2}$ carbonate bands was determined at $1720-1585,1200-900$, and $890-830 \mathrm{~cm}^{-1}$, respectively, to calculate the phosphate/amide I $\left(\mathrm{PO}_{4} /\right.$ amide I) and carbonate/phosphate $\left(\mathrm{CO}_{3} / \mathrm{PO} 4\right)$ ratios $[15,16]$.

For crystallinity index $\left(\mathrm{CI}_{\mathrm{FTIR}}\right)$, the intensity of splitting $v_{4}$ doublet phosphate bands $\approx 600$ and $560 \mathrm{~cm}^{-1}$ was calculated after deconvolution of the spectra at region $700-500 \mathrm{~cm}^{-1}$ using Shemesh method $[17,18]$.

2.3. Scanning Electron Microscopy/Energy Dispersed X-Ray (SEM/EDX) Analysis. The dentin samples were mounted on aluminium stubs and sputtered with gold coating. The surface morphology and elemental composition of each sample were examined by SEM/EDX (field emission gun, Quanta 250, FEI, Czechoslovakia) to evaluate the changes induced by root canal sealers. Three reading of elemental composition was captured from each specimen. The calcium/phosphate $(\mathrm{Ca} / \mathrm{P})$ ratio was calculated.

2.4. X-Ray Diffraction (XRD) Analysis. The dentin specimens were milled to fine power and subjected to $\mathrm{XRD}$ analysis (XRD, Empyrean, Analytical 2010, Holland) at $40 \mathrm{kV}$ and $35 \mathrm{~mA}$, to determine the hydroxyapatite phases of dentin. The XRD pattern was collected from 2 to $60^{\circ}$ of $2 \theta$ at a scan rate $2 \%$ min. To calculate the crystallinity \% (C\% $\mathrm{XRD})$, the sum of total intensities of diffraction peaks $\left(I_{\text {net }}\right)$ and the sum of all measured intensity $\left(I_{\text {tot }}\right)$ including amorphous phase and air scatter $\left(I_{\text {scat }}\right)$ were calculated from XRD pattern. The following equation was used [19]:

$$
\mathrm{C}_{\mathrm{XRD}}=100 \cdot \sum \frac{I_{\text {net }}}{\sum I_{\mathrm{tot}}-\sum I_{\mathrm{scat}}} .
$$

2.5. Statistical Analysis. The data of FTIR $\left(\left(\mathrm{CO}_{3} / \mathrm{PO}_{4}, \mathrm{PO}_{4} /\right.\right.$ amide $\mathrm{I})$ and crystallinity index $\left.\left(\mathrm{CI}_{\mathrm{FTIR}}\right)\right), \mathrm{EDX}(\mathrm{Ca} / \mathrm{P}$ ratio) and crystallinity percent of XRD $(\mathrm{C} \% \mathrm{XRD})$ were statistically analyzed by One-Way ANOVA and Tukey post hoc test. The statistical analysis was carried at 0.05 significance using SPSS WIN (20.0; SPSS, Munich, Germany).

\section{Results}

3.1. Fourier Transform Infrared (FTIR) Spectroscopy Analysis. Figure 1 showed the FTIR spectra of all groups stored in either PBS (A and B) or deionized water (C and D) for 60 days. In comparison to control untreated dentin, the spectra of dentin treated with HiFlow detected some changes in intensity and/or shift of amide I, $v_{1} v_{3}$ phosphate, and $v_{2}$ 


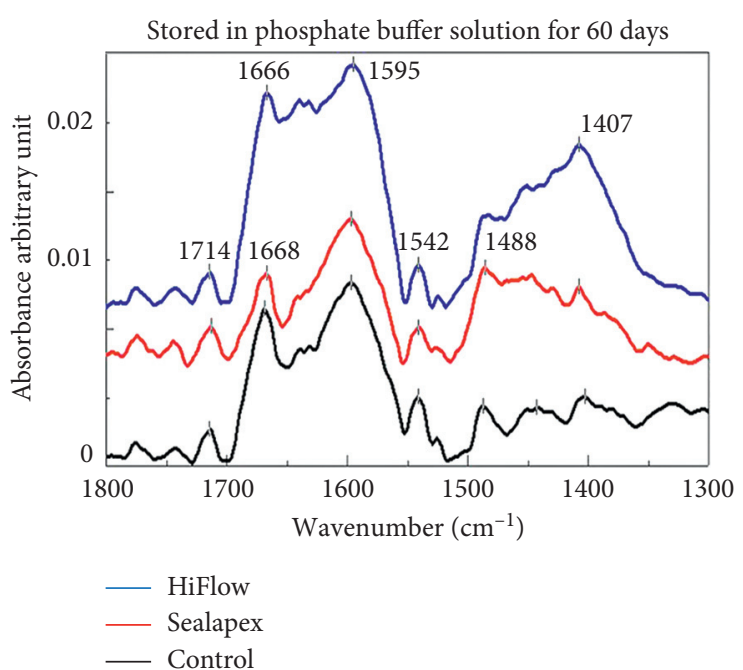

(a)

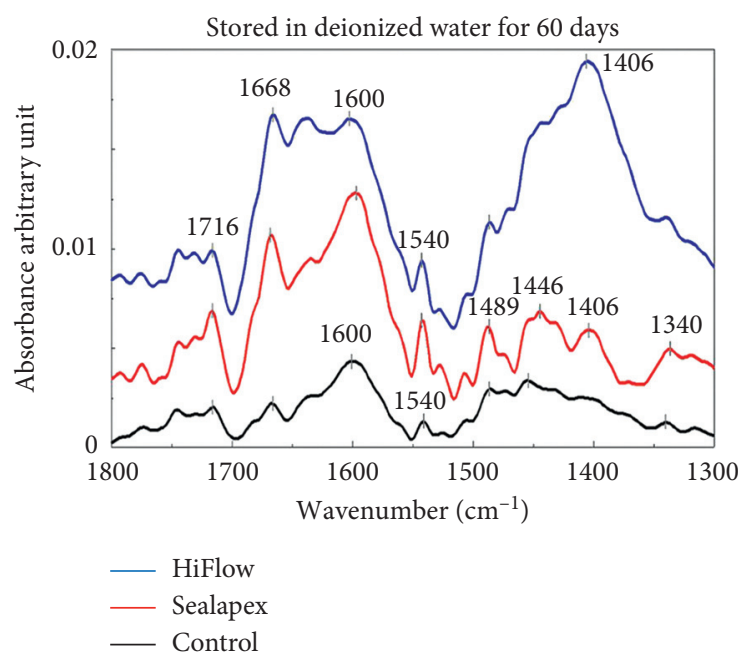

(c)

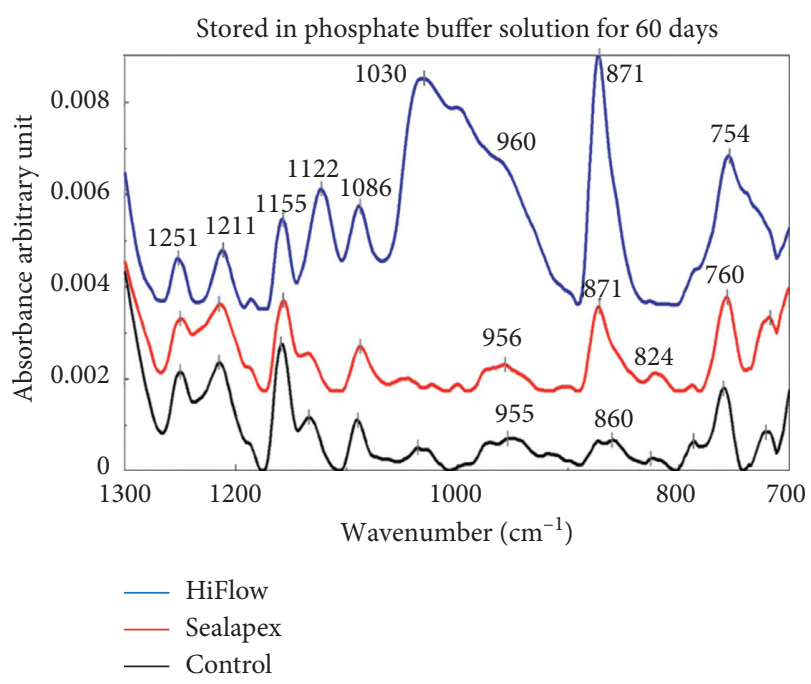

(b)

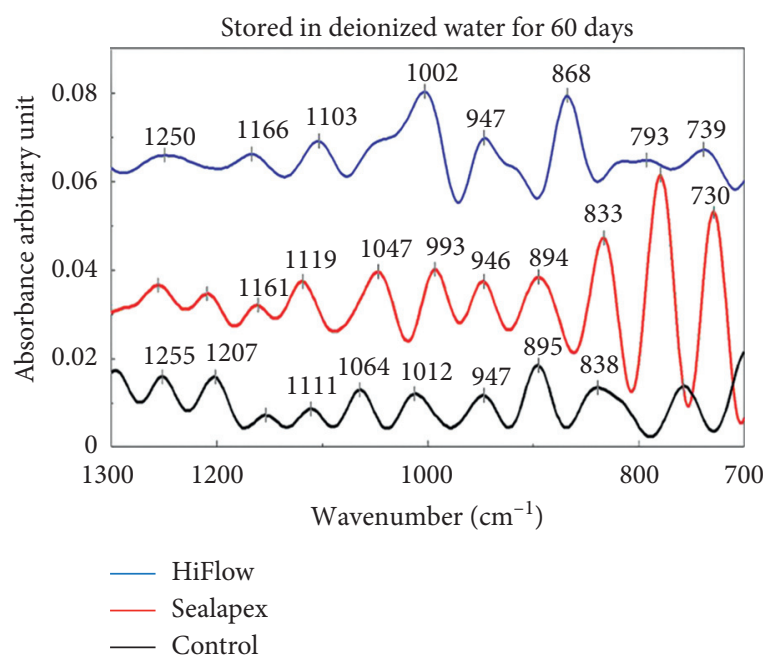

(d)

FIGURE 1: Fourier transform infrared spectra of the dentin samples: the spectra of HiFlow-treated dentin, either stored in phosphate buffer solution ( $\mathrm{a}$ and $\mathrm{b}$ ) or deionized water ( $\mathrm{c}$ and $\mathrm{d}$ ) for 60 days, showed some changes in intensity and/or shift of amide I $v_{1} v_{3}$ phosphate and $v_{2}$ carbonate bands (at $1720-1580$ and $1200-900$ and $890-830 \mathrm{~cm}^{-1}$, respectively) compared with untreated dentin. No obvious change was observed in spectra of Sealapex-treated dentin.

carbonate bands (at 1720-1580, 1200-900, and $890-830 \mathrm{~cm}^{-1}$, respectively), whereas there was no significant changes in spectra of dentin treated with Sealapex except in $v_{2}$ carbonate bands at $890-830 \mathrm{~cm}^{-1}$ which showed increase in the intensity, the same as the HiFlow sealer.

The mean \pm standard deviation values of all parameters extracted from FTIR spectra of all groups were described in Table 1. In general, there is no significant difference between all groups stored in either deionized water or PBS. In specimen stored in PBS, the HiFlow induced insignificant increase in the mean value of integrated area under amide I and $v_{1} v_{3}$ phosphate $(3.194 \pm 0.68$ and $0.970 \pm 0.23$, respectively) and significant increase in the mean value of $v_{2}$ carbonate $(0.427 \pm 0.27)$ as compared with untreated dentin $(2.78 \pm 0.3,0.873 \pm 0.06$ and $0.084 \pm 0.01$ respectively) at $P>0.05$, whereas Sealapex induced insignificant decrease in amide $I(2.297 \pm 0.52)$ at $P=0.206$, significantly decrease in $v_{1} v_{3}$ phosphate $(0.239 \pm 0.07)$ at $P \leq 0.001$ and no significant change in $v_{2}$ carbonate $(0.087 \pm 0.04)$ at $P=1.000$ (Table 1$)$.

There was no significant difference in mean values of phosphate/amide I ratio obtained in untreated dentin and HiFlow-treated dentin $(0.317 \pm 0.0 .4$ and $0.314 \pm 0.1$, respectively) $(P=1.000)$, whereas the Sealapex-treated dentin exhibited significant reduction in the mean value of phosphate/amide I ratio $(0.117 \pm 0.07$ at $P=0.009)$. The mean value of carbonate/phosphate $\left(\mathrm{CO}_{3} / \mathrm{PO}_{4}{ }^{3-}\right.$ FTIR $)$ ratio was significantly increased by both HiFlow $(0.44 \pm 0.23)$ and Sealapex sealers $(0.375 \pm 0.11)$ as compared with untreated dentin $(0.096 \pm 0.01)(P \leq 0.001)$, with no significant difference between both sealers $(P>0.05)$ (Table 1$)$.

Figure 2 showed the deconvolution of spectra at $700-500 \mathrm{~cm}^{-1}$ of dentin stored in PBS (A) and deionized water (B) for 60 days. The spectra of HiFlow-treated dentin showed changes in band intensity of $v_{4}$ doublet phosphate 
TABLE 1: Mean \pm standard deviation values of all parameters extracted from FTIR spectra of all investigated dentin stored in either phosphate buffer solution or deionized water for 60 days; these parameters include integrated area under bands of amide I, $v_{1} v_{3}$ phosphate, $v_{2}$ carbonate (at $1720-1580,1200-900$, and $890-830 \mathrm{~cm}^{-1}$ ), and phosphate/amide I and carbonate/phosphate ratio.

\begin{tabular}{lcccccc}
\hline $\begin{array}{l}\text { Stored solution for } \\
60 \text { days }\end{array}$ & \multicolumn{3}{c}{ Phosphate buffer solution } & & \multicolumn{2}{c}{ Deionized water } \\
Groups & $\begin{array}{c}\text { Untreated } \\
\text { dentin }\end{array}$ & $\begin{array}{c}\text { HiFlow-treated } \\
\text { dentin }\end{array}$ & $\begin{array}{c}\text { Sealapex-treated } \\
\text { dentin }\end{array}$ & $\begin{array}{c}\text { Untreated } \\
\text { dentin }\end{array}$ & $\begin{array}{c}\text { HiFlow-treated } \\
\text { dentin }\end{array}$ & $\begin{array}{c}\text { Sealapex-treated } \\
\text { dentin }\end{array}$ \\
\hline Amide I area & $2.78 \pm 0.3$ & ${ }^{*} 3.194 \pm 0.68$ & $2.297 \pm 0.52$ & $2.392 \pm 0.59$ & ${ }^{\dagger} 1.989 \pm 0.38$ & $2.66 \pm 0.06$ \\
$v_{1} v_{3}$ phosphate area & $0.873 \pm 0.06$ & ${ }^{*} 0.970 \pm 0.23$ & $0.239 \pm 0.07$ & $0.741 \pm 0.18$ & $0.778 \pm 0.51$ & ${ }^{\dagger} 0.248 \pm 0.03$ \\
$\begin{array}{l}v_{2} \text { carbonate area } \\
\text { Phosphate/amide I } \\
\text { ratio }\end{array}$ & $0.084 \pm 0.01$ & ${ }^{*} 0.427 \pm 0.27$ & $0.087 \pm 0.04$ & $0.079 \pm 0.03$ & $0.271 \pm 0.2$ & $0.079 \pm 0.02$ \\
$\begin{array}{l}\text { Carbonate/ } \\
\text { phosphate ratio }\end{array}$ & $0.317 \pm 0.0 .4$ & $0.314 \pm 0.1$ & $0.117 \pm 0.07$ & $0.323 \pm 0.09$ & ${ }^{*} 0.412 \pm 0.27$ & $0.093 \pm 0.01$ \\
\hline
\end{tabular}

${ }^{*}$ The significant greatest value. ${ }^{\dagger}$ The significant lowest value.

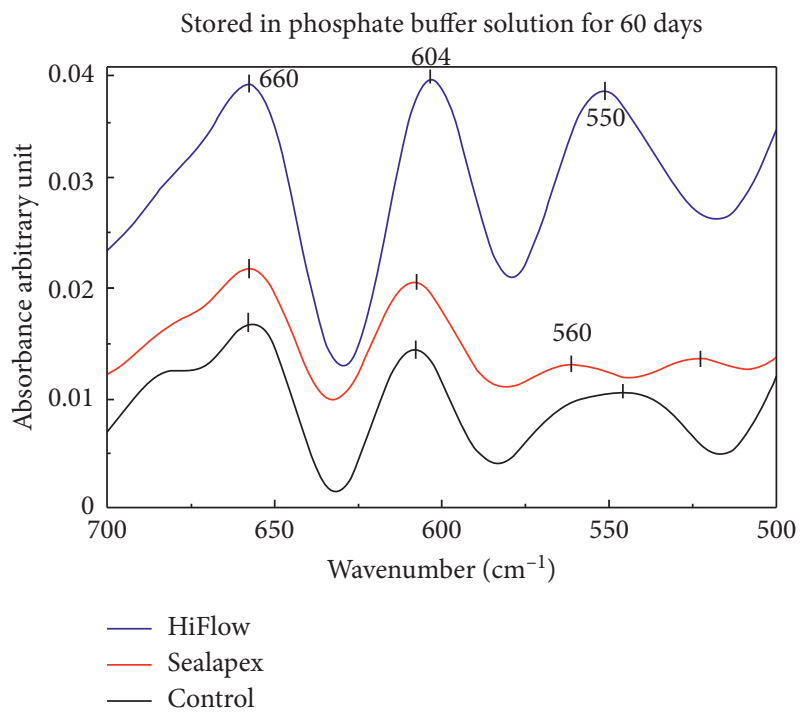

(a)

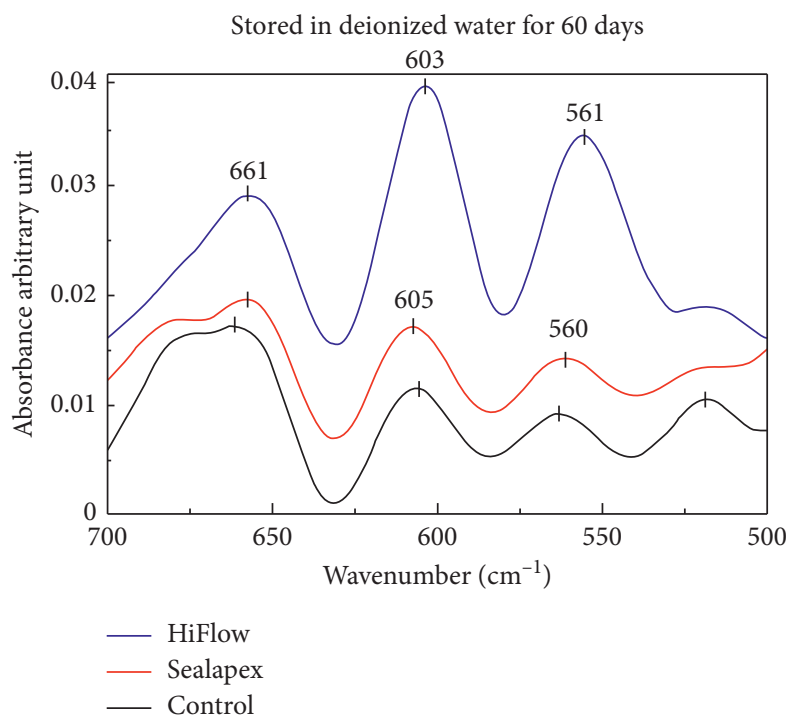

(b)

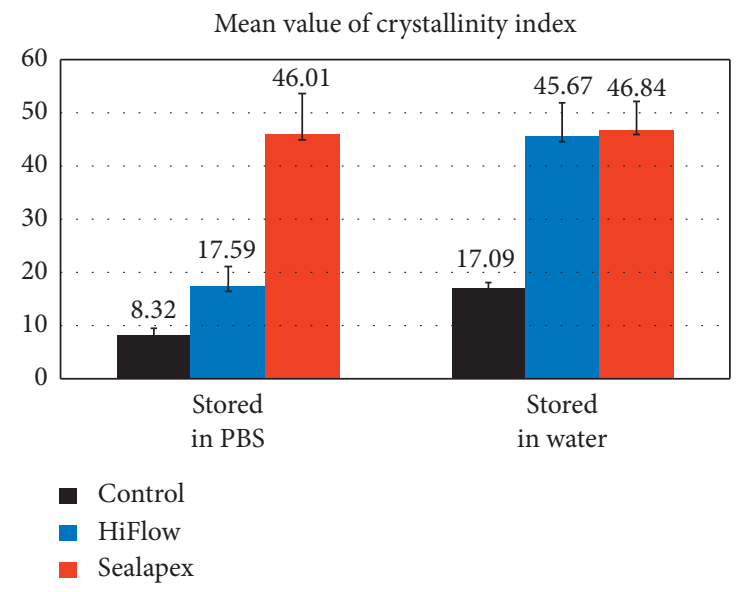

(c)

FIGURE 2: FTIR spectra of dentin stored in phosphate buffer solution (a) and deionized water (b) for 60 days. Both sealers induced increases in the mean value of crystallinity index $\left(\mathrm{CI}_{\mathrm{FTIR}}\right)$ as compared with control untreated dentin $(\mathrm{c})$.

bands at $604 \mathrm{~cm}^{-1}$, whereas no obvious changes were noticed in the spectra of Sealapex-treated dentin as compared with the spectra of untreated dentin.
The $\mathrm{CI}_{\mathrm{FTIR}}$ extracted from FTIR at splitting $v_{4}$ doublet phosphate bands $\approx 600$ and $560 \mathrm{~cm}^{-1}$ for both storage media, PBS and deionized water, was significantly increased with 
HiFlow sealer $(17.59 \pm 3.4$ and $45.67 \pm 6.04$, respectively) and Sealapex sealer ( $46.01 \pm 8.1$ and $46.84 \pm 5.1$, respectively) as compared to untreated dentin $(8.32 \pm 1.16$ and $17.09 \pm 1.04$, respectively) at $P \leq 0.001$ (Figure $2(\mathrm{c})$ ).

\subsection{Scanning Electron Microscope/Energy Dispersed X-Ray} (SEM/EDX) Analysis. Scanning electron microscope analysis of untreated dentin revealed no obvious changes on the surface morphology compared to dentin treated with either HiFlow or Sealapex sealer in both storage media.

The dentin's chemical composition evaluated by EDX analysis was explained in Figure 3. For the control untreated dentin, there were no significant changes in mean values (weight \%) of calcium content, phosphate content, and calcium/phosphate ratio when stored in PBS (43.33 \pm 3.26 , $15.13 \pm 1.9$ and $2.92 \pm 0.5$, respectively) or deionized water $(40.09 \pm 4.11,14.67 \pm 1.51$ and $2.76 \pm 0.38$ respectively) for 60 days. With the tested groups stored either in PBS or in deionized water, the mean value of calcium constituents was significantly decreased after treatment by both HiFlow (34.87 \pm 6.85 and $24.17 \pm 3.21$, respectively) and Sealapex $(26.57 \pm 4.1$ and $27.31 \pm 1.97$, respectively) at $P \leq 0.001$ (Figure $3(\mathrm{~g}))$. However, the mean value of phosphate constituent was significantly decreased by both HiFlow and Sealapex sealers when stored in deionized water $(11.67 \pm 0.84$ and $8.61 \pm 0.91$, respectively) at $P \leq 0.001$. However, when dentin was stored in PBS for 60 days, the mean phosphate constituent significantly increased by HiFlow $(16.01 \pm 3.62)$ but decreased by Sealapex sealer $(11.28 \pm 1.34)(P \leq 0.001)$ (Figure $3(\mathrm{~h})$ ). Regarding $\mathrm{Ca} / \mathrm{P}$ ratio, when deionized water was the storage medium, HiFlow group exhibited a significant reduction in the mean value $(2.05 \pm 0.17)$ while Sealapex group exhibited a great mean value $(3.19 \pm 0.27)$ at $P \leq 0.001$. When PBS was storage medium, there was significant reduction of $\mathrm{Ca} / \mathrm{P}$ ratio by both HiFlow and Sealapex sealers $(2.27 \pm 0.76$ and $2.36 \pm 0.28$, respectively) compared with untreated dentin $(P \leq 0.001)$ (Figure 3(i)).

3.3. X-Ray Diffraction (XRD) Analysis. All investigated dentin specimens contain fluorapatite crystalline phase (Ca5 F (P O4)3, card No: 00-012-0261) and minor of magnesium calcium carbonate ((Mg.064 Ca.936) (CO3), card No: 01086-2335) stored in either PBS or deionized water (Figures 4(a) and 4(b)). In general, the crystalline fluorapatite was detected in untreated dentin at 21.1, 26.6, 29.6, $31.8,32.11,33.05$, and $39.67^{\circ} 2 \theta$. When PBS is used, the spectra showed reduction in band intensity at 29.6 and $39.67^{\circ} 2 \theta$ with HiFlow-treated dentin and massive reduction in band intensity at 29.6 and $49.6^{\circ} 2 \theta$ with Sealapex-treated dentin, whereas dentin stored in deionized water showed a marked reduction in band intensity at $26.6^{\circ} 2 \theta$ with both sealer groups and a new band at $28.2^{\circ} 2 \theta$ with HiFlow-treated dentin.

Regarding the crystallinity percent, there was a significant increase in the mean value when dentin is stored in PBS for 60 days $(P \leq 0.001)$ than those stored in deionized water except with Sealapex-treated dentin (Figure 4(c)). The untreated and HiFlow-treated dentin stored in PBS for 60 days exhibited significant great mean values $(96.6 \pm 3.73$ and $90.93 \pm 6.54$, respectively) with no significant difference between them $(P=0.278)$, whereas Sealapex induced the significant lowest value $(80.689 \pm 5.99)$ at $P \leq 0.001$ (Figure 4(c)).

\section{Discussion}

Dentin crystallinity refers to the degree of mineral crystal in hydroxyapatite phase within the dentin structure [20]. It is related to calcium phosphate crystals deposition inside or between collagen fibers [21]. Both mineral and organic composition have an impact on the mechanical properties of dental structure [20]. Root canal sealer may compromise the mineral constituents and crystallinity of dentin. The Phosphate/amide I ratio ${ }_{\mathrm{FTIR}}$, carbonate/phosphate ratio ${ }_{\mathrm{FTIR}}$, and calcium/phosphate ratio EDX $_{\text {are }}$ quantitative measures to indicate the mineral and collagen dentin constituents [22]. Crystalline index $\left(\mathrm{CI}_{\mathrm{FTIR}}\right)$ and crystallinity percent $(\mathrm{C} \% \mathrm{XRD})$ are quantitative measures to indicate the mineral crystallinity [22, 23].

With the use of deionized water, there was no significant difference between the untreated dentin and HiFlow- or Sealapex-treated dentin in most of the parameters extracted from FTIR spectra. The integrated area under $v_{1} v_{3}$ phosphate was decreased with Sealapex and increased with HiFlow sealer. This finding may be attributed to the lack of phosphate ingredient in Sealapex sealer. Otherwise, the phosphate content in HiFlow sealer may serve as phosphate supplement for treated dentin. This finding was confirmed by EDX analysis. Moreover, both sealers induced a significant increase in carbonate/phosphate ratio ${ }_{\text {FTIR }}$ of dentin. This finding may be related to the increase in the intensity of $v_{2}$ carbonate band at $890-830 \mathrm{~cm}^{-1}$ by both sealers and further increase in the intensity of $v_{1} v_{3}$ phosphate band at $1200-900 \mathrm{~cm}^{-1}$ by HiFlow sealer.

Calcium hydroxide plays a rule in sealer-dentin interaction. Sealapex is a calcium hydroxide-based sealer that induced decreases in amide I area. The dentin reaction to such a sealer is mainly influenced by the sealer solubility and dissociation into calcium and hydroxyl ions; the higher diffusion of dissociated ions through the radicular dentin, the higher dentinal $\mathrm{pH}[7,24,25]$. Desai and Chandler proved that Sealapex exhibited higher ion dissociation within 2 hours in moisture environment [7]. Thus, the prolonged setting time and high $\mathrm{pH}$ of Sealapex sealer (10.4-10.6) [25] can promote degradation of the organic content of dentin [7] and disrupt the link between the collagenous network and hydroxyapatite crystals [9]. HiFlow sealer is bioceramic sealer that follows the pozzolanic reaction and release calcium hydroxide as a by-product of its hydration reaction [26]. Although, with PBS, it exhibited increase in amide I area, this finding may be attributed to its bioactivity that acts as a barrier for organic degradation.

The current study showed reverse relationship between the crystallinity index $\left(\mathrm{CI}_{\mathrm{FTIR}}\right)$ and the crystallinity percent (C\%XRD). There was no significant difference on untreated dentin when stored in PBS or deionized water. The 


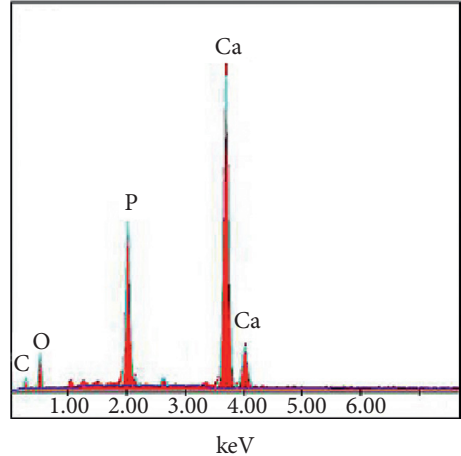

(a)

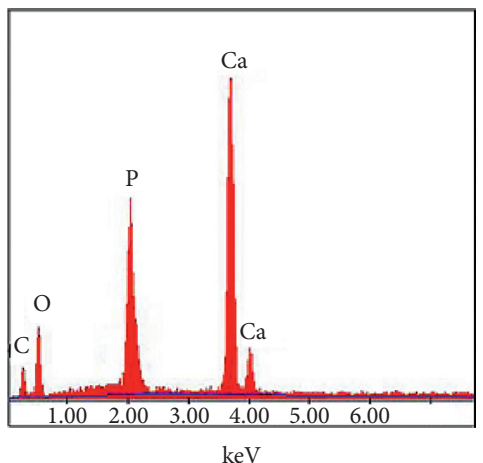

(d)

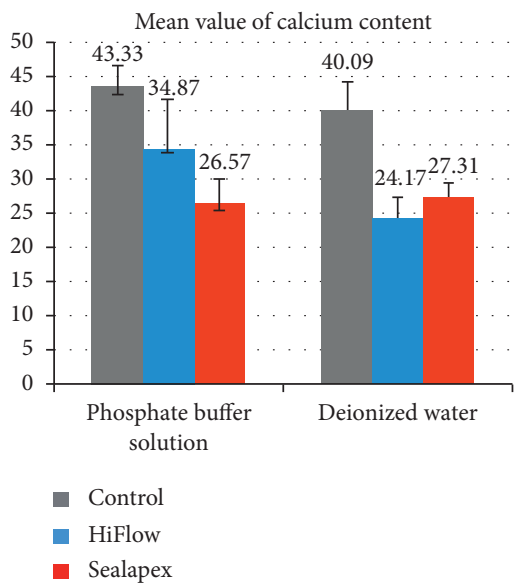

(g)

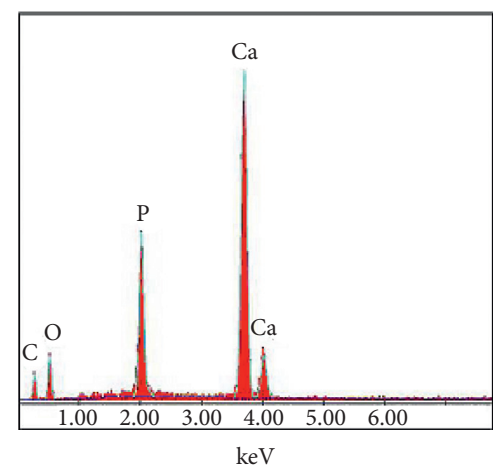

(b)

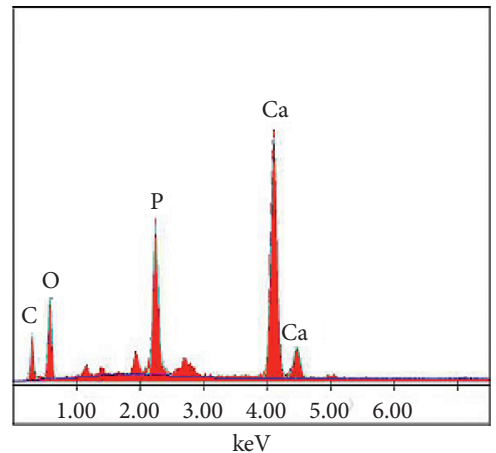

(e)

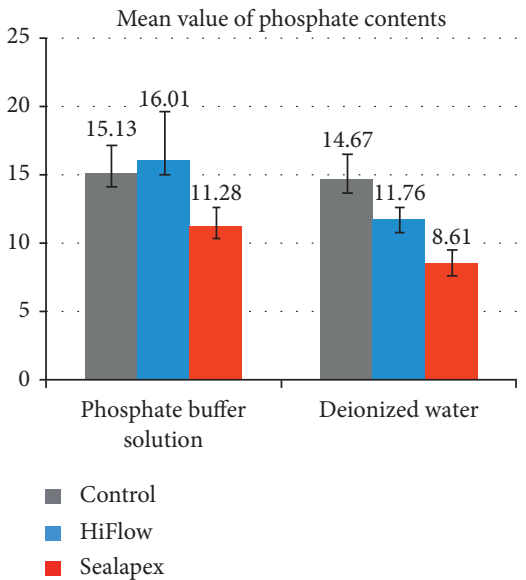

(h)

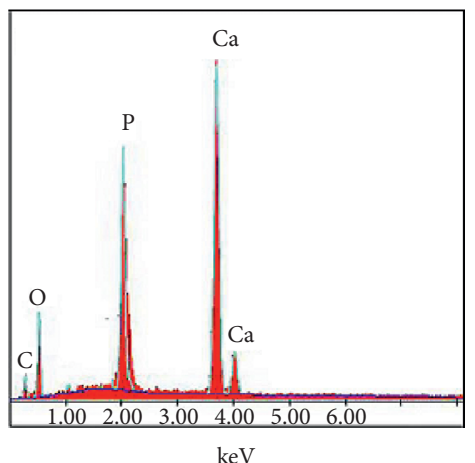

(c)

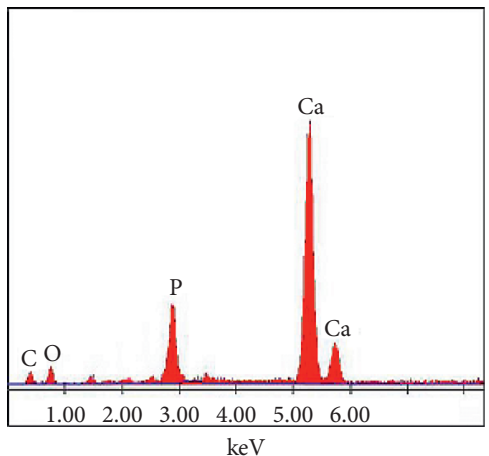

(f)

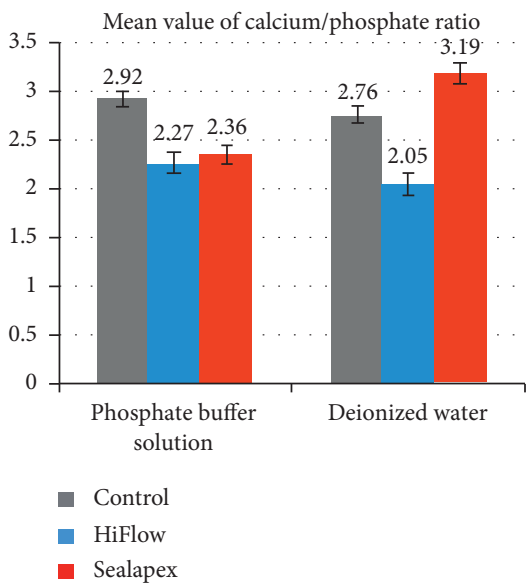

(i)

Figure 3: The EDX analysis of untreated dentin (a-b) and dentin treated with HiFlow (c-d) and Sealapex (e-f) stored in either PBS or deionized water for 60 days. There were changes in means of calcium (g) and phosphate (h) constituents (weight\%) as well as calcium/ phosphate ratio (i) of radicular dentin treated with root sealers compared with control untreated dentin stored in either phosphate buffer solution or deionized water for 60 days.

difference was detected in sealers-treated dentin. The PBS storage medium, which simulates the clinical situation, may improve the HiFlow performance on dentin due to bioactivity properties. Compared to untreated dentin, the $\mathrm{CI}_{\mathrm{FTIR}}$ significantly increased with both sealers, however, the $\mathrm{C}$ \% XRD insignificantly decreased by HiFlow and markedly decreased by Sealapex. The C\%XRD is related to the crystal structure of the dentin, whereas the $\mathrm{CI}_{\mathrm{FTIR}}$ is related to the intensity of $v_{4}$ phosphate band at 604,590 , and $560 \mathrm{~cm}^{-1}$ $[17,18]$. Otherwise, the C\% XRD was based on hydroxyapatite phases that were high in untreated dentin. The decrease of $\mathrm{C}$ $\%_{\mathrm{XRD}}$, by both sealers, may be attributed to the organic degradation that allows the loose of phosphate element by the effect of calcium hydroxide by-product.

When the PBS was the storage media, the changes of dentin $\mathrm{C}_{\mathrm{XRD}}$ and $\mathrm{CI}_{\mathrm{FTIR}}$ induced by HiFlow were not significant. The phosphate buffer solution is considered as supplementary medium for phosphate element and provides the material bioactivity [8] that helps in dentin strength. 


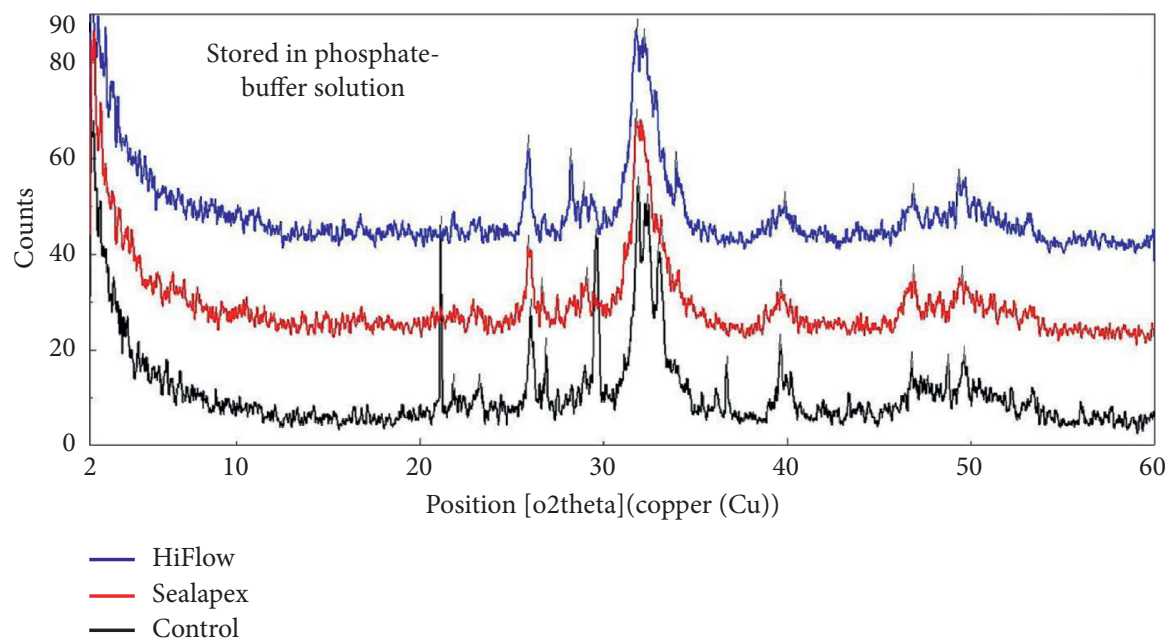

(a)

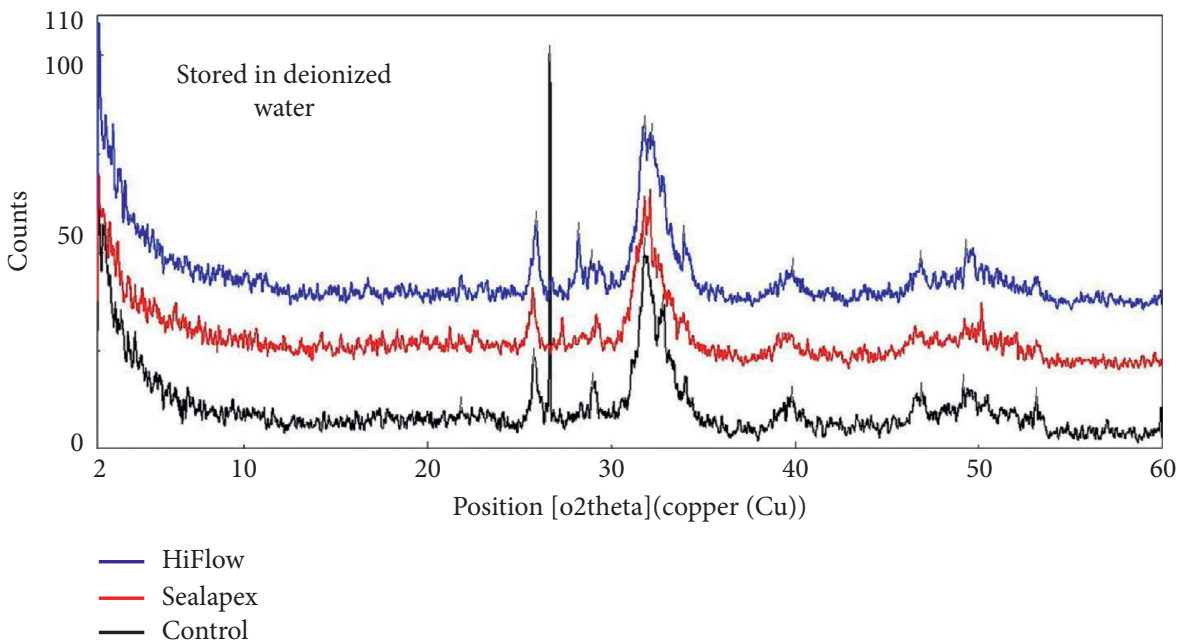

(b)

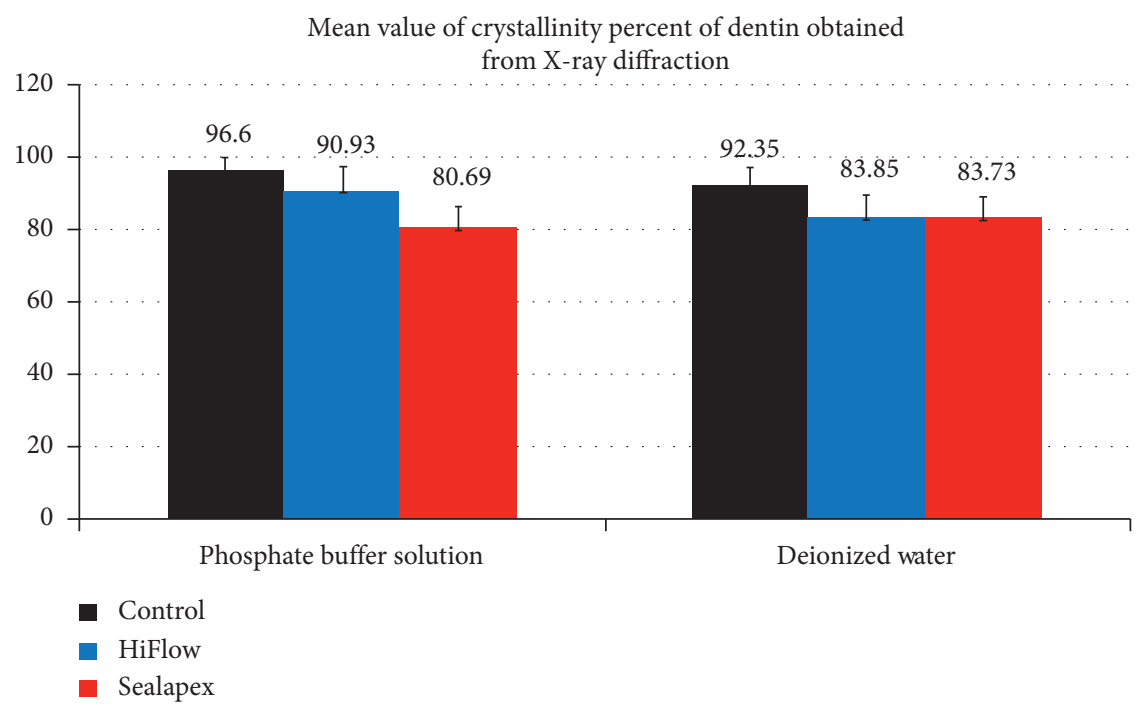

(c)

FIGURE 4: X-ray diffraction pattern showing the crystalline fluorapatite phases of untreated, HiFlow-treated dentin and Sealapex-treated dentin, stored in phosphate buffer solution (a) and deionized water (b) for 60 days, respectively. The crystallinity percent was decreased with tested sealers (c). 


\section{Conclusion}

Under the circumstances of the current study, both HiFlow and Sealapex sealers induced changes in mineral constituents and crystallinity of treated dentin. Accordingly, the null hypothesis was rejected. The PBS storage medium, which mimics clinical condition, improved the chemical structure of sealers treated dentin, particularly when bioceramic sealer was used. Although long-term treatment with HiFlow sealer induced changes in amide I, phosphate, carbonate, and calcium content of treated dentin, there were no significant changes in $\mathrm{CI}_{\mathrm{FTIR}}$ and $\mathrm{C} \%$ XRD compared to untreated dentin, whereas the long-term Sealapex treatment induced marked changes in $\mathrm{CI}_{\mathrm{FTIR}}$ and $\mathrm{C} \% \mathrm{XRD}$ of treated dentin.

\section{Data Availability}

The authors accept that the all readers can access the data supporting the conclusions of the study and clearly outline the reasons.

\section{Conflicts of Interest}

The authors declare that there are no conflicts of interest.

\section{Acknowledgments}

This project was funded by The Deanship of Scientific Research (DSR) at King Abdulaziz University, Jeddah, Saudi Arabia, under Grant no. G-147-165-39. The authors, therefore, acknowledge with thanks DSR for technical and financial support.

\section{References}

[1] A. Kishen, "Mechanisms and risk factors for fracture predilection in endodontically treated teeth," Endodontic Topics, vol. 13, no. 1, pp. 57-83, 2006.

[2] A. Kishen, "Biomechanics of fractures in endodontically treated teeth," Endodontic Topics, vol. 33, no. 1, pp. 3-13, 2015.

[3] M. W. Jameson, J. A. A. Hood, and B. G. Tidmarsh, "The effects of dehydration and rehydration on some mechanical properties of human dentine," Journal of Biomechanics, vol. 26, no. 9, pp. 1055-1065, 1993.

[4] C. J. Soares, F. R. Santana, N. R. Silva, J. C. Preira, and C. A. Pereira, "Influence of the endodontic treatment on mechanical properties of root dentin," Journal of Endodontics, vol. 33, no. 5, pp. 603-606, 2007.

[5] D. Orstavik, "Materials used for root canal obturation: technical, biological and clinical testing," Endodontic Topics, vol. 12, no. 1, pp. 25-38, 2005.

[6] H.-M. Zhou, Y. Shen, W. Zheng, L. Li, Y.-F. Zheng, and M. Haapasalo, "Physical properties of 5 root canal sealers," Journal of Endodontics, vol. 39, no. 10, pp. 1281-1286, 2013.

[7] S. Desai and N. Chandler, "Calcium hydroxide-based root canal sealers: a review," Journal of Endodontics, vol. 35, no. 4, pp. 475-480, 2009.

[8] S. T. Abu Zeid, R. A. Alamoudi, E. A. Abou Neel, and A. A. Mokeem Saleh, "Morphological and spectroscopic study of an apatite layer induced by fast-set versus regular-set endosequence root repair materials," Materials, vol. 12, no. 22, p. $3678,2019$.
[9] J. O. Andreasen, B. Farik, and E. C. Munksgaard, "Long-term calcium hydroxide as a root canal dressing may increase risk of root fracture," Dental Traumatology, vol. 18, no. 3, pp. 134-137, 2002.

[10] G. H. Yassen and J. A. Platt, “The effect of nonsetting calcium hydroxide on root fracture and mechanical properties of radicular dentine: a systematic review," International Endodontic Journal, vol. 46, no. 2, pp. 112-118, 2013.

[11] S. T. H. Abu Zeid, M. G. Khafagi, and E. A. Abou Neel, "Effect of root canal medications on maturation and calcification of root canal dentin' hydroxyapatite," Spectroscopy Letters, vol. 49, no. 2, pp. 135-139, 2016.

[12] B. Rosenberg, P. E. Murray, and K. Namerow, "The effect of calcium hydroxide root filling on dentin fracture strength," Dental Traumatology, vol. 23, no. 1, pp. 26-29, 2007.

[13] A. N. Sawyer, S. Y. Nikonov, A. K. Pancio et al., "Effects of calcium silicate-based materials on the flexural properties of dentin," Journal of Endodontics, vol. 38, no. 5, pp. 680-683, 2012.

[14] J. White, W. Lacefield, L. Chavers, and P. Eleazer, "The effect of three commonly used endodontic materials on the strength and hardness of root dentin," Journal of Endodontics, vol. 28, no. 12, pp. 828-830, 2002.

[15] M. J. Turunen, S. Saarakkala, L. Rieppo, H. J. Helminen, J. S. Jurvelin, and H. Isaksson, "Raman and FTIR spectroscopic measurements provide complementary information on development of bone composition during maturation in rabbits," in Proceedings of the Annual Conference of the Orthopaedic Research Society, New Orleans, LA, USA, 2010.

[16] D. Farlay, G. Panczer, C. Rey, P. D. Delmas, and G. Boivin, "Mineral maturity and crystallinity index are distinct characteristics of bone mineral," Journal of Bone and Mineral Metabolism, vol. 28, no. 4, pp. 433-445, 2010.

[17] S. T. Abu Zeid, N. M. Alamoudi, M. G. Khafagi, and E. A. Abou Neel, "Chemistry and bioactivity of NeoMTA plus versus MTA angelus root repair materials," Journal of Spectroscopy, vol. 2017, Article ID 8736428, 9 pages, 2017.

[18] M. Lebon, I. Reiche, J.-J. Bahain et al., "New parameters for the characterization of diagenetic alterations and heat-induced changes of fossil bone mineral using fourier transform infrared spectrometry," Journal of Archaeological Science, vol. 37, no. 9, pp. 2265-2276, 2010.

[19] M. Ermrich and D. Opper, XRD for the Analyst, Getting Acquainted with the Principles, 2nd edition, Panalytical, Almelo, Netherlands, 2013, http://www.panalytical.com.

[20] J. Reyes-Gasga, O. Koudriavtseva, R. Herrera-Becerra, and A. Escobosa, "XRD characterization of crystallinity of human tooth enamel under influence of mechanical grinding," Materials Sciences and Applications, vol. 6, no. 6, pp. 464-472, 2015.

[21] A. Slimani, F. Nouioua, A. Desoutter et al., "Confocal Raman mapping of collagen cross-link and crystallinity of human dentin-enamel junction," Journal of Biomedical Optics, vol. 22, no. 8, Article ID 086003, 2017.

[22] J. Reyes-Gasga, E. L. Martínez-Piñeiro, G. Rodríguez-Álvarez, G. E. Tiznado-Orozco, R. García-García, and E. F. Brès, "XRD and FTIR crystallinity indices in sound human tooth enamel and synthetic hydroxyapatite," Materials Science and Engineering: C, vol. 33, no. 8, pp. 4568-4574, 2013.

[23] Y. Sa, Y. Guo, X. Feng et al., "Are different crystallinity-indexcalculating methods of hydroxyapatite efficient and consistent?" New Journal of Chemistry, vol. 41, no. 13, pp. 57235731, 2017.

[24] R. A. Fidel, M. D. Sousa Neto, J. C. Spanó, E. L. Barbin, and J. D. Pécora, "Adhesion of calcium hydroxide-containing root 
canal sealers," Brazilian Dental Journal, vol. 5, no. 1, pp. 53-57, 1994.

[25] N. Faria-Júnior, M. Tanomaru-Filho, F. L. C. V. Berbert, and J. Guerreiro-Tanomaru, "Antibiofilm activity, $\mathrm{pH}$ and solubility of endodontic sealers," International Endodontic Journal, vol. 46, no. 8, pp. 755-762, 2013.

[26] S. T. Abu Zeid, A. A. Mokeem Saleh, M. G. E.-D. Khafagi, and E. A. Abou Neel, "Setting reaction of new bioceramic root canal sealers," Spectroscopy Letters, vol. 51, no. 8, pp. 426-430, 2018. 